\title{
A Suggested Model for Teaching EFL to Syrian Refugee Learners in Egypt
}

\author{
Mohamed Farrag Ahmed Badawi \\ Faculty of Education, October 6 University, Egypt \\ E-mail: badawi1us@yahoo.com
}

Cite this article as: Badawi, M. F. A. (2021). A Suggested Model for Teaching EFL to Syrian Refugee Learners in Egypt. International Journal of Second and Foreign Language Education, 1(1), 28-41. https://doi.org/10.33422/ijsfle.v1i1.61

\begin{abstract}
Syrian refugee learners are allowed to join Egyptian governmental schools. However, some Egyptian teachers cannot meet Syrian refugee learners' needs. Most of the teachers are unaware of refugee responsive teaching competencies (RRTCs). Accordingly, the present study attempted to identify Syrian refugee learners' needs and refugee responsive teaching competencies to suggest a refugee responsive teaching competencies model (RRTCM). The study utilized a pre-post onegroup design. The study recruited ( $n=76)$ EFL student teachers from October 6 University, $(n=21)$ Syrian refugee learners, and 64 in-service teachers of refugees. For data collection, a refugee learners' needs assessment questionnaire and a refugee responsive teaching competencies knowledge test (RRTCKT) were developed. Findings revealed that the Syrian refugee learners identified 21 needs involving safety, social, cultural, psychological, personal, and educational needs. The suggested refugee responsive teaching model was effective in developing EFL student teachers' RRTCs knowledge.
\end{abstract}

Keywords: refugee learners, needs assessment, EFL Egyptian context, responsive teaching

\section{Introduction}

The influx of Syrian refugee has exceeded the capacities of many host countries. Egypt is one of the countries hosted refugees from different nationalities. According to UNHCR (2019), nearly 50\% of the refugees in Egypt are Syrians who represent $57 \%$ of the total number of the officially registered refugees. Egypt encounters educational difficulties to host such growing numbers of Syrian refugees. Because of teaching refugees is an ethical commitment, Egypt deals with both Syrian refugee learners and Egyptian learners alike. In actuality, there is no camp education in Egypt for refugee learners. Although they study the same curriculum of Egyptian learners, the educational situation is not so rosy. Both teachers of refugee and refugee learners are facing many difficulties. Generally, refugee learners face numerous forms of discrimination and receive poor education (Watkins, Noble, and Wong 2018). Younes and Morrice (2019) mention that Syrian refugee children report that they are suffering from bullying, humiliation, physical abuse, psychological distress and discrimination, which have been key reasons for drop out. Refugee teachers cannot have access to any professional development program in the host countries and employment in schools is rare. Thus, the great majority of refugee learners prefers refugee community centers to governmental public schools that offer inadequate education to refugee learners (Kostoulas-Makrakis and Makrakis, 2020).

Reviewing the current Egyptian EFL teacher preparation programs reveals that EFL teachers receive little, if any, training in teaching refugees. The pedagogical courses of many Egyptian EFL teacher

(C) The Author(s). 2021 Open Access. This article is distributed under the terms of the Creative Commons Attribution 4.0 International License, which permits unrestricted use, distribution, and redistribution in any medium, provided that the original author(s) and source are credited. 
preparation programs pay a little attention to teaching refugees. Therefore, many EFL teacher have shaky awareness of refugee learners' needs such as academic, cultural, psychological and emotional needs. Egyptian teachers of refugee and refugee teachers need more training to be aware of the refugees' traumatic experience and cultural backgrounds. Kostoulas-Makrakis and Makrakis (2020) mention that there is a lack of effective professional development for teachers to cope with refugee education. According to Karam et al (2017), many teachers of refugee are not well trained and lack the awareness and experiences to teach the refugee learners in a formal class. For example, teaching EFL to refugee learners in multi-culture classrooms is not easy for untrained EFL teachers. However a large number of studies have been conducted to identify the potential problems and challenges of refugees in learning EFL, Syrian refugees' educational challenges are marginalized (Ogilvie \& Fuller, 2016; Cinkara, 2017; Steele, 2017). Previous educational research on refugee learners is rather limited (Pastoor 2016). Bonin (2017) mentions that educational research on refugee learners is fragmented. Although it is widely known that teachers play a fundamental role in the delivery of quality education, few studies have examined EFL teachers' role in refugee and crisis contexts. Well-trained EFL teachers could achieve successful integration of refugees to promote social inclusion, reduce tensions and create more equal community (Organization for Economic Co-operation and Development, OECD, 2019). So, there is a need to identify Syrian refugee learners' needs and develop EFL student teachers' refugee responsive teaching competencies awareness.

\section{Literature review}

\section{Refugee learners' needs}

Refugee learners have some specific needs. To maintain effective teaching and learning, EFL teachers have to recognize these needs. For example, refugee learners need to resume their study. They need to be safe. They need to communicate with others; they also need to belong to their home country and the host country. These needs help refugee learners to overcome their sense of loss and trauma. Accordingly, identifying and responding to the refugee learners' needs should be considered as a key issue in refugee education. As for refugee learners need to resume their education, Essomba (2017) argues that many refugee children have experienced interrupted education. They need to learn a new language and literacy skills (Birman and Tran, 2017). Handling academic material in the classroom is one of the specific refugee educational challenges (Cassity and Gow, 2005). Dooley (2009) adds another refugee specific need that is dealing with concepts and references that are culturally and socially unfamiliar. Furthermore, refugee learners need to feel belonging. Nakeyar, Esses and Reid (2017) state that refugee learners are separated from their home country peers and are required to establish new friendships in the host country. Additionally, Sleijpen et al. (2016) mention that refugees feel alienated and experience difficulties to develop a sense of belonging. Making friendship is especially challenging for refugee children and youth (Correa-Velez, Gifford \& McMichael, 2015).

Additionally, refugee learners need to develop their personal identities. Identity construction supports the integration of refugee learners in schools and societies. According to Nakeyar, Esses and Reid (2017), refugee learners need strong personal identities to cope with their home and host cultures. Finding the right balance between home and host cultures could be one of the basic needs of refugee learners. Nevertheless, coping with the host society culture does not mean that the refugee learners' values, language, dialect, thinking, and history have to be marginalization or underestimated. Refugee learners need to feel that both teachers and classmates appreciate their previous lives and heritage. Moreover, refugee learners need to feel safe. Many refugee learners have experienced war, conflict and 
unsafe environments and thus need to feel safe in the host countries. Schools can be safe shelters for refugee learners (Matthews, 2008). Schools have to provide refugee newcomers with safe spaces for positive interactions and effective learning opportunities. Nakeyar, Esses and Reid (2017) mention that if refugees do not feel welcome and safe in their new country, they would not be able to achieve academic outcomes. Refugee learners are subject to experience unfair treatment, racial insults, and intellectual belittling. Juvonen \& Bell (2018) state that research has revealed that education is important for the psychological accommodation of refugee children. School environment is very important for the socialization and the integration of refugee or immigrant with native learners. Kovinthan (2016) argues that refugee learners are willing to be in safe and welcoming classrooms. School success is largely dependent on teachers' awareness of refugees' values, practices, and attitudes.

Most of refugee learners have experienced violent conflict, loss of home and degraded types of education (MacNevin, 2012). Many refugee learners are mentally and emotionally unprepared to face the challenges in the new host destinations. The experience is difficult for refugees who are coping with their trauma and disturbance. Teachers, in particular, have to be trauma expert to provide the necessary support for the newcomers to feel valued. Stewart (2011) elaborates that classroom teachers need to be aware of three transitional periods that can affect student learning outcomes. Finally, refugees are subject to be affected by trauma and pain, which, can considerably impact the construction and the development of refugees' personal identities. Therefore, they need education with a strong emotional and affective constituent, which sometimes schools and teachers are not able to supply (Essomba, 2017). Refugee learners lost their homeland, properties, friends and relatives. They might also have been exposed to traumatic events including war (Carlson, Cacciatore and Klimek, 2012). Many refugee learners suffer from emotional and mental health problems. According to Jacobsen, Demott and Heir (2014), depression, anxiety or sleep disturbance, often in combination, are more common in refugee learners than in the general population. In addition, Graham, Minhas and Paxton (2016) notice that refugee learners face several risk factors in their new learning environments. According to Harrison Lowman (2016), learners who are experiencing post-traumatic stress disorder should be safe in meaningful classrooms

\section{Refugee Learners' Pedagogical Background}

Identifying and responding to refugee learners' needs cannot be fully understood without recognizing refugee learners' pedagogical background. It is refugee learners' pedagogical background that enhances their academic and social integration in the host country schools. That is to say, to provide quality education to refugee learners, teachers should be aware of the refugees' pedagogical background. Frimberger (2016) illustrates that the level of education obtained by the refugee learners in their home country plays a crucial role in learning the target foreign language. Alefesha and Al-Jamal (2019) remark that teachers have a significant role in teaching the refugee learners because it is a critical task to teach the individuals who came from different family, cultural, educational and country backgrounds.

Rajab (2015) describes the Syrian classroom practices stating that Syria classrooms are mainly teacher-centered, where the physical layout is uniform, with fixed double desks and attached chairs. He adds that teaching was highly teacher dominated in Syrian EFL classes and teachers did not diversify their teaching styles to promote pair or group work in the classroom. According to Rajab, there was a lack of pedagogical understanding of the importance of meaningful classroom talk that invites learners to play an active role in the discourse. Catarina and Maaike (2019) report that Syrian EFL teachers prefer to keep the barrier between the teacher and the student in order to avoid some problems. In Syria, 
the teacher is the only source of information. Syrian teacher is the only one who speaks. There is no communication between the teacher and the student. The teacher asks questions and gives correct answers. Such concise review on refugee learners' pedagogical background assures some refugees' needs such as refugee educational needs, personal identity and belonging needs, protection and safety needs, psychological needs, cultural social needs and emotional needs. Procedurally, these needs used as guidelines for constructing the Syrian refugee learners' needs assessment questionnaire.

\section{Refugee Responsive Teaching Competencies Model (RRTCM)}

Culturally responsive teaching (CRT) stems from sociocultural theory. Sociocultural theory is grounded in the premise that cognitive development is mediated through the use of culturally constructed practices, tools, and symbols (Vygotsky 1978). Consequently, EFL awareness is shaped through social interaction and practice which in turn facilitate EFL development. Instructional supports allow learners to use their cultural backgrounds to achieve mastery (Swain et al., 2015). Culturally responsive teachers recognize the value of incorporating culture, language, heritage and home community experiences with teaching process, which improves students' academic achievement. CRT exploits students' cultural and linguistic knowledge and uses these strengths as a platform to foster higher-level thinking skills (Gay, 2018). Culturally responsive teachers serve as cultural mediators by building strong and warm working relationships between school and community to advance their goal of creating culturally responsive learning environments (Martin, 2006). CRT highlights the role of refugees' background and lived experiences in supporting their schooling experience in the host country. In addition, CRT helps teachers of refugees to afford welcoming and inclusive classrooms for every student. Although the current conceptualization of CRT is somewhat appropriate for teaching refugee learners, it does not cover all the refugee learners' needs. Therefore, proposing a refugee responsive teaching model is required to bridge the gap in the literature of refugee education with a special reference to teaching EFL to refugee learners.

Kostoulas-Makrakis \& Makrakis (2020), mention that refugee learners find the community centers more suitable because their teachers are Syrians because Egyptian teachers lack the knowledge and skills to tackle the needs of refugee learners. Thus, recognizing refugee learners' needs and understanding their pedagogical background may help EFL teachers of refugee better teach refugees in multi-cultural classrooms. Qualified teachers are ready to meet refugee learners' academic, cultural and social needs. Indeed, teachers can have an immense influence on refugee education (Bush \& Saltarelli, 2000). While teachers have great potential to positively affect children's lives, in some contexts their limited professional orientation may hinder such possibilities since some teachers can be abusive and disempowering (Kirk \& Winthrop, 2007). Teachers require more training on holistic education models to be able to meet learners' academic and non-academic needs and challenges (Bunar et al., 2018). To teach refugees or multi-cultural classrooms, teachers have to have specific competencies and skills. Furthermore, well-trained teachers are vital for the inclusion of refugee learners. Yet, they need support in order to manage multicultural classes, often including learners with psychosocial needs (Crul, et al., 2019, p42).

Furthermore, Culbertson \& Constant (2015) state that teachers were generally unprepared to handle traumatized Syrian learners in Middle East Countries. Bunar et al. (2018) mention that teachers need several competences to teach in diverse classrooms with immigrants and refugees. In Germany, Italy, Spain and Sweden, teachers may be trained and certified but need new skills to address the needs of refugees. Alefesha \& Al-Jamal (2019) suggest that teachers who teach the refugees, require appropriate 
training and other professional support to enable effective course delivery for the benefit of the teacher and learners According to Mogli, Kalbeni and Stergiou (2020), the education of refugee learners constitutes a challenge, as their experiences and needs are multifaceted. Consequently, teachers need more training to become more diversity-aware to better respond to the needs of refugee learners (Magos \& Margaroni, 2018). Karam, Kibler and Yoder (2017) mention that teachers' poor skills often impose challenges to teaching EFL to the Syrian refugees. Sarmini, Topcu, Scharbrodt (2020), declare that one area of concern for most teachers is their lack of specialized training in addressing these traumatic experiences of their learners.

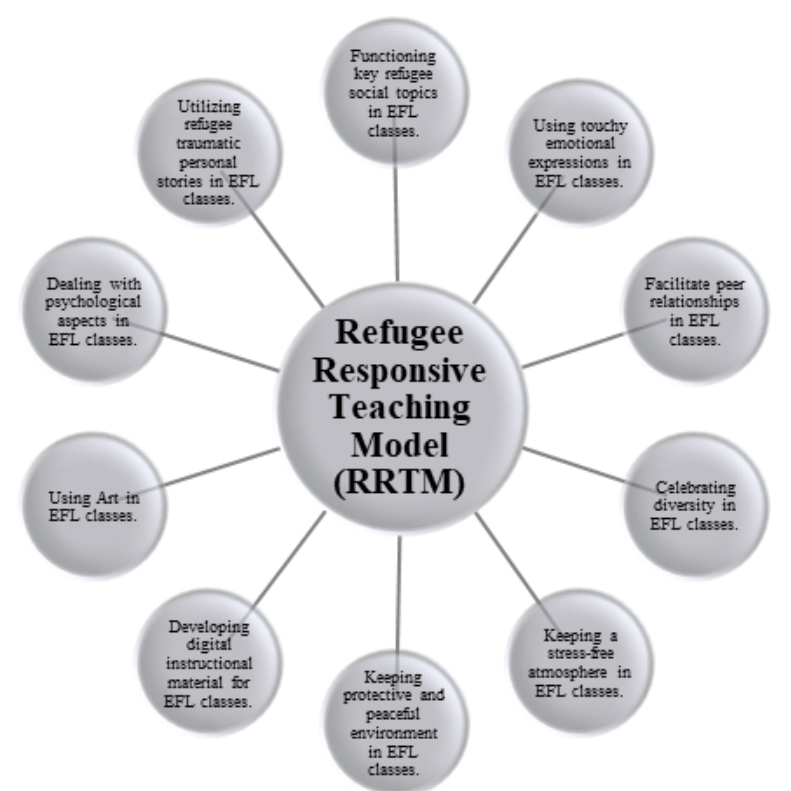

Figure 1. Refugee Responsive Teaching Model (RRTCM)

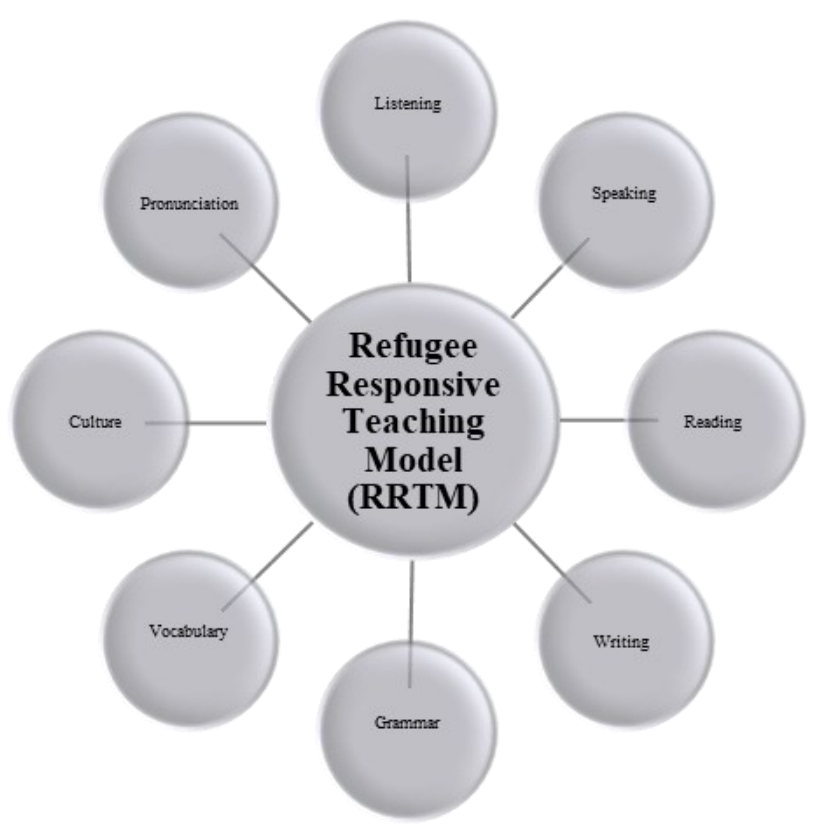

Figure 2. RRTCM and EFL Skills/Areas

The proposed RRTM focuses on ten specific refugee teaching competencies (Fig.1). The first competency is functioning refugee social topics in EFL classes. EFL teachers should be able to use 
refugee names, habits, traditions, food and dressing while teaching to support refugee leaners and develop their EFL descriptive writing, speaking and grammar. The second competency is using touchy emotional expressions in EFL classes. EFL teachers should be able to use emotional expressions with refugee learners in greetings, praising and sympathy in teaching vocabulary and communication skills. The third competency is facilitating peer relationships in EFL classes. EFL teachers should be able to use language functions to start conversations, gaming and group working to develop personal and speaking skills. The fourth competency is celebrating diversity in EFL classes. EFL teachers should be able to provide equal opportunities to each leaner to express his/her ideas equally and freely orally or in writing. The fifth competency is keeping a stress-free atmosphere in EFL classes. EFL teachers should be able to use jokes and comics with special reference to the superior aspects of refugee cultures to develop their sense of belonging and home cultural values. The sixth competency is keeping protective and peaceful environment in EFL classes. EFL teachers should be able to explain refugee rights and the school code of ethics to develop EFL learners' speaking, listening and reading skills. The seventh competency is developing digital instructional material for EFL classes. EFL teachers should be able to use Youtube videos, stories, TV programs that highlight the best practices of refugees to develop their speaking, listening, pronunciation, culture and reading skills. The eighth competency is using Art in EFL classes. EFL teachers should be able to use pictures, drawings, songs and music highlighting culture diversity to develop EFL learners' communication and culture skills. The ninth competency is dealing with psychological aspects in EFL classes. EFL teachers should be able to deal with refugees' psychological problems as sons, brothers and guests using encouraging expressions. The tenth competency is utilizing refugee traumatic personal stories in EFL classes. EFL teachers should be able to utilize refugee traumatic stories to develop speaking, writing and vocabulary skills.

More importantly, the RRTM (Fig.2) covers almost all EFL skills: listening, speaking, reading, writing, grammar, vocabulary, pronunciation and culture. The proposed RRTM helps EFL teachers meet the key needs of refugee learners.

\section{Context of the problem}

The researcher is well-acquainted with refugee learners' and teachers' background knowledge since he is currently the coordinator of the project of the Refugee Teaching Certification Programme for Egyptian and Syrian Refugee Teachers sponsored by EU and October 6 University, Egypt. One of the project gained expertise is that a 'one-size-fits-all' approach does not work when it comes to teaching refugee learners. Since there is no camp education in Egypt, Syrian refugees are granted full access to public education. Both Syrians and Egyptians speak the same language with a slight different accent. However, there are some difficulties facing both refugee learners and teachers alike. Teachers do not possess all the competencies required for teaching EFL to refugee learners or working in multi-culture classrooms. Thus, they cannot meet the basic needs of the refugee learners. The Egyptian curriculum does not give attention to the Syrians' needs.

\section{Problem of the study}

Whereas Syrian refugee learners represent a considerable population in the public, private, international, and community centers in Egypt, EFL teachers did not receive intended formal training in teaching refugee learners and multi-culture classrooms. As a result, most of EFL student teachers need training on refugee learners' needs and refugee responsive teaching competencies. 


\section{Questions of the study}

The study attempted to answer the following questions:

1) What are the key Syrian refugee learners' needs?

2) What are the key refugee responsive teaching competencies?

3) What is the effect of the proposed model on developing EFL student teachers' refugee responsive teaching competencies?

\section{Aim of the study}

The aim of the present study is propose a refugee responsive teaching model (RRTCM) to help EFL student teachers better EFL to refugee learners in multi-culture classrooms.

\section{Hypothesis of the Study}

Based on the literature review and the study questions, the study attempted to test the following hypothesis: There is a statistically significant difference between EFL student teachers' mean scores on the pre refugee responsive teaching knowledge test (RRTKT) and their mean scores on the post (RRTKT) favoring the post administration.

\section{Significance of the Study}

The present study attempts to explore Syrian refugee learners' needs and EFL student teachers' refugee responsive teaching competencies. In addition, the study is concerned with developing EFL student teachers' refugee responsive teaching competencies. The study has some theoretical and practical contributions. Theoretically, the study provides an in-depth profile on teaching EFL to Syrian refugees in Egypt. Practically, the study suggests a new RRTM for Arab refugees fled to Arab host country where the native language is the same. The study provides a list of Syrian refugee learners' needs that can be adopted for developing curriculum and teaching methodology. Moreover, a list RRT Competencies is to be prepared, which can be used for designing any training course in the future in EFL refugees context. The RRTM can be used as an integral part of the current EFL preparation program. With slight modification, the suggested RRT Module can be used as a training package for training pre-service and in-service teachers of all majors. Finally, the study may be one of the pioneer studies tackling teaching EFL to refugees and multi-culture classrooms.

\section{Method}

\section{Participants}

The study participants were recruited as an intact group which involved ( $\mathrm{n}=76)$ EFL student teachers, October 6 University. Participants' age was ranging from 21 to 22 years old. Another group of participants included $(n=21)$ Syrian refugee learners from 9 schools in October 6 City. Their age was ranging from 12 to 15 years old. Since October 6 City hosts a huge number of Syrian population, recruiting Syrian refugee learners was not an easy duty. This is because Syrian refugee learners prefer Syrian Community Centers to the Egyptian public schools. Also, the few number of Syrian refugee learners may be due to Covid-19 restrictions. In addition, $(n=64)$ teachers who are teaching Syrian refugee learners and Egyptian learners were recruited and participated in identifying refugee needs and teaching competencies. 
Table 1.

Study participants

\begin{tabular}{|c|c|c|c|c|c|}
\hline \multirow{2}{*}{ Participants } & \multirow{2}{*}{ n. } & \multirow{2}{*}{ Affiliation } & \multicolumn{2}{|c|}{ Gender } & \multirow{2}{*}{ Participation Aim } \\
\hline & & & M. & F. & \\
\hline EFL student teachers & 76 & October 6 University & 32 & 44 & Experimentation \\
\hline Syrian refugee learners & 21 & $\begin{array}{l}\text { Egyptian Preparatory Public Schools, October } \\
6 \text { City. }\end{array}$ & 11 & 10 & Needs Assessment \\
\hline \multirow{2}{*}{ Teachers of refugee } & \multirow{2}{*}{64} & Egyptians: Egyptian Public Schools & 26 & 6 & \multirow{2}{*}{$\begin{array}{c}\text { Identifying RRT } \\
\text { Competencies }\end{array}$} \\
\hline & & Syrian: Syrian Community Centers & 21 & 11 & \\
\hline
\end{tabular}

\section{Design of the Study}

The study utilized pre and post one-group design where the participants (EFL student teachers) were pre tested before the intervention instructional unit and post tested after the intervention. While the RRT Module was the independent variable, EFL student teachers' RRT knowledge was the dependent variable.

\section{Instruments}

The current study developed a need assessment questionnaire for identifying Syrian refugee learners' needs and an EFL student teachers' refugee responsive teaching competencies test

\section{Syrian Refugee Learners' Needs Assessment Questionnaire (SRLNAQ)}

Table.2.

Syrian Refugee Learners' Needs Distribution

\begin{tabular}{|l|l|l|}
\hline Needs Domain & Items & Weight \\
\hline Safety Needs & 2 & $9.5 \%$ \\
\hline Social Needs & 3 & $14.3 \%$ \\
\hline Cultural Needs & 3 & $14.3 \%$ \\
\hline Psychological Needs & 4 & $19 \%$ \\
\hline Personal Needs & 2 & $9.5 \%$ \\
\hline Educational Needs & 7 & $33.4 \%$ \\
\hline 6 & 21 & $100 \%$ \\
\hline
\end{tabular}

The SRLNAQ was designed to identify Syrian refugee learners' needs. It consists of 21 items covering 6 domains: safety needs, social needs, cultural needs, psychological needs, personal needs and educational needs. Each need domain should gain "importance rate percentage" equals $70 \%$ or more to pass. The content of the SRLNAQ was validated by 5 EFL specialists. As a pilot procedures, the reliability of the SRLNAQ measured by the test-retest reliability where the questionnaire was given to the same participants ( 8 Syrian Refugee Learners) twice at different times to see if the scores are the same. According to Pearson correlation coefficient was $(\mathrm{r}=0.8)$.

\section{Refugee Responsive Teaching Competencies Knowledge Test (RRTCKT)}

The RRTCKT was designed to assess EFL student teachers' refugee responsive teaching competencies knowledge. It consists of $30 \mathrm{MCQ}$ questions covering 10 refugee responsive teaching competencies: functioning refugee social topics in EFL classes, using touchy emotional expressions in EFL classes, facilitating peer relationships in EFL classes, celebrating diversity in EFL classes, keeping a stress-free atmosphere in EFL classes, keeping protective and peaceful environment in EFL classes, developing digital instructional material for EFL classes, using Art in EFL classes, dealing with psychological aspects in EFL classes, utilizing refugee traumatic personal stories in EFL classes (Fig. 1). 
The content of the RRTCKT was validated by 5 EFL specialists. The reliability of the RRTCKT measured by test-retest reliability where the test was administered to the same participants (20 EFL student teachers) twice at different times. Using Pearson correlation coefficient, the reliability of the test was $(\mathrm{r}=0.9)$. The test was scored according to zero -or-one procedure; while a wrong response was given zero and the correct response was give one point. A higher score indicates a higher level of EFL student teachers' Refugee Responsive Teaching competencies knowledge.

\section{Refugee Responsive Teaching Competencies Unit (RRTCU)}

Based on the proposed refugee responsive teaching competencies model (RRTCU), a refugee responsive teaching competencies unit (RRTCU) was designed and implemented. The main aim of the RRTCU is to develop EFL student teachers' refugee responsive teaching competencies knowledge. The instructional unit includes 3 instructional sessions. Session one provides the trainees with a solid theatrical background knowledge on refugees' conditions, refugee learners' needs and refugees' educational background. Session two aims to familiarizing the trainees with refugees' responsive teaching competencies. Session three provides the trainees with the procedures of aligning refugees' responsive teaching competencies to teaching EEL skills. The instructional material includes content documents, reading list, Youtube Videos and PowerPoint presentations. To deliver the unit content, PPP was used as a basic instructional technique. Alternative assessment (digital presentation, group reports, peer assessment and self-assessment) was adopted to evaluate the unit learning outcomes.

\section{Procedure}

In the beginning of the study, 64 in-service teachers who teaching refugee learners were interviewed to gain insight on Syrian refugee learners' pedagogical background, host school challenges and refugees' needs. By the end of the of the revision meeting, the participants were asked to write the most important statements in the revision meeting. Such an informal report was used in refining and stating some learners' needs items.

As for the implementation procedures of the Syrian refugee learners' needs assessment questionnaire (SRLNAQ), the researcher ${ }^{1}$ is well-acquainted with the schools that have refugee learners. Accordingly, it was possible to visit 9 schools in October 6 City to anticipate Syrian refugee learners' needs. The Syrian refugee learners' needs assessment questionnaire (SRLNAQ) was administered in Arabic to make it easy for the Syrian refugee learners to respond to the questionnaire. In addition, oral instructions and explanations were offered to resolve any misunderstanding. Within an hour, almost all the participants responded to the questionnaire items. After two weeks, Syrian refugee learners' needs assessment questionnaire (SRLNAQ) was re-administered to the same participants and approximately under the same conditions.

\section{- RRTCKT}

With respect to the refugee responsive teaching competencies knowledge test, the researcher was teaching TEFL Course to the EFL fourth year students (Section: A), thus this section was selected as an intact group. In the beginning of the first term of the academic year 2020-2021, the RRTCKT was administer to the EFL fourth year EFL students and they were asked to respond the test items seriously. After 45 minutes, the test was collected and scored. Due to the fact that the October 6 University adopts

\footnotetext{
${ }^{1}$ A coordinator of the project of the Refugee Teaching Certification Programme for Egyptian and Syrian Refugee Teachers sponsored by EU and October 6 University.
} 
blended learning, the proposed unit was delivered online using Zoom and WhatsApp facilities. Accordingly, the intervention /instructional unit was offered online. The unit consists of three sessions. Each session lasts for two hours. The unit offers some well-selected topics covering refugees' conditions, refugees' needs, refugees' educational background, and RRT competencies. The instructional unit material targeted refugee teaching competences. The proposed instructional unit material includes content documents, reading list and Youtube Videos. The unit content was sent to the participants digitally. The participants' assignments and activities were sent to the WhatsApp group managed by researcher. After finishing the training Unit, the participants were post tested. The implementation of the unit was in the first term of the academic year 2020/2021. While the unit lasted for 6 contact hours, it required intensive self-study at home on the part of the trainees.

\section{Data analysis}

For analyzing of the quantitative data of the present study, the researcher used the t-test to compare the differences between mean scores of EFL student teachers on the pre application of the refugee responsive teaching knowledge test (RRTKT) and their mean sores on the post application of the RRTKT. In addition, the effect size of the refugee responsive teaching competencies unit (RRTCU) was online calculated using Cohen's d. Similarly, for analyzing of the quantitative data gained by the Syrian refugee learners' needs assessment questionnaire (SRLNAQ), the researcher used the t-test to compare the differences between the mean scores of the Syrian refugee learners on the (SRLNAQ) and their mean sores on the post application of the SRLNAQ.

\section{Results}

\section{Results of Syrian Refugee Learners' Needs Assessment Questionnaire (SRLNAQ)}

Table 3.

Syrian Refugee Learners' Repose to Needs Assessment Questionnaire (SRLNAQ)

\begin{tabular}{|l|c|c|c|c|}
\hline \multirow{2}{*}{ Needs Domains } & \multicolumn{2}{|c|}{$\begin{array}{c}\text { Importance Rating } \\
\text { Percentage }\end{array}$} & $\begin{array}{c}\text { Required } \\
\text { Percentage }\end{array}$ & \multirow{2}{*}{ Result } \\
\cline { 2 - 3 } & Pre & $\boldsymbol{P}$ Post & & Pass \\
\hline Safety Needs & $82.9 \%$ & $82 \%$ & & Pass \\
\hline Social Needs & $73.3 \%$ & $75.3 \%$ & \multirow{2}{*}{$70 \%$} & Pass \\
\hline Cultural Needs & $83 \%$ & $81 \%$ & & Pass \\
\hline Psychological Needs & $87.6 \%$ & $92.4 \%$ & & Pass \\
\hline Personal Needs & $78.1 \%$ & $75.3 \%$ & & Pass \\
\hline Educational Needs & $88.6 \%$ & $89.5 \%$ & & Pass \\
\hline Total Percentage & $82.2 \%$ & $82.4 \%$ & & Pass \\
& & & & \\
\end{tabular}

Table 3 shows that the six domain of the Syrian refugee learners' needs passed the importance percentage cut-off level (70\%) on both the pre and post administration of the SRLNAQ. It is also clear that the total percentages of the pre and post administration are almost identical $(82.2 \%)$ and $(82.4 \%)$ respectively.

Table 4.

Differences between Syrian Refugee Learners'scores on the pre and post SRLNAQ

\begin{tabular}{|l|c|c|c|c|c|c|}
\hline Administration & N & M & SD & df & t & P \\
\cline { 1 - 3 } Pre & 21 & 24.67 & 10.85 & \multirow{2}{*}{40} & & \multirow{2}{*}{0.9772} \\
\hline Post & 21 & 24.76 & 10.64 & & & \\
\hline
\end{tabular}


Table 4 displays that the difference between the Syrian refugee learners' scores on the pre and post SRLNAQ is considered to be statistically insignificant because $t=0.0286$ and $P=0.9772$. This result revels that Syrian refugee learners' are aware of their needs. Coupling results in tables 1111 to those of table 2222 provides an answer to the first study question wherever twenty-one needs and 6 domains were identified.

\section{Results of Refugee Responsive Teaching Competencies Knowledge Test (RRTCKT)}

Table 5.

Differences between Syrian Refugee Learners' scores on the pre and post RRTCKT

\begin{tabular}{|l|c|c|c|c|c|}
\hline Administration & N & M & SD & t & P \\
\cline { 1 - 4 } Pre & 76 & 10.3 & 4.36 & \multirow{2}{*}{22.84} & $<0.0001$ \\
\hline Post & 76 & 25.1 & 3.59 & & \\
\hline
\end{tabular}

Table 5 shows that the difference between EFL student teachers' scores on the pre and post RRTCKT is considered statistically significant because $t$ value $=22.84$ and $\mathrm{P}<0.0001$. This result reveals that the refugee responsive teaching competencies model (RRTCM) was effective in developing EFL students' teachers' refugee responsive teaching knowledge. This result verifies the study hypothesis that there is a statistically significant differences between EFL student teachers' mean scores on the pre RRTCKT and their mean scores on the post RRTCKT favoring the post administration. In addition, this result answers the third question of the study.

\section{Discussion}

Syrian refugee learners are permissible to join public Egyptian schools, yet most of the Egyptian EFL teachers lack skills to meet Syrian refugee learners' needs. They are also do not master all specific refugee responsive teaching competencies (RRTCs). Accordingly, the present study attempted to identify both Syrian refugee learners' needs and refugee responsive teaching competencies to propose a RRTCM, which in turn help EFL student teachers better teach Syrian refugee learners and multi-culture classrooms. The study findings revealed that the identified Syrian refugee learners' needs were safety needs, social needs, cultural needs, psychological needs, personal needs and educational needs. More importantly, the suggested RRTCM was effective in improving EFL prospective teachers' knowledge of refugee responsive teaching competencies. Another finding was that refugees' needs are consistent with the findings obtained by other researchers (Younes \& Morrice, 2019; Juvonen \& Bell, 2018; Nakeyar, Esses and Reid, 2017). In addition, results of refugee responsive teaching competencies go partially in line with the findings of other researchers (Swain et al., 2015; Bunar et al., 2018; Kostoulas-Makrakis \& Makrakis, 2020; Kalbeni and Stergiou, 2020).

Remarkably, although Syrian Refugee Learners were young (12-15 years old), they could successively respond to the Syrian refugee learners' needs assessment questionnaire (SRLNAQ). This could be partially rendered to the Arabic version of the SRLNAQ was readable. The detailed oral instructions explaining the items of the SRLNAQ might facilitate responding to the items. The suggested needs were well-selected from the relevant literature. The written report of the 64 Egyptian and Syrian teachers of refugees supported the questionnaire items. The researcher's experience in refugee education could make the items more clear. Finally, Syrian refugee learners' actual suffering was behind their identical performance on the pre and post administration of the SRLNAQ.

Before offering the intervention unit, EFL prospective teachers' knowledge of refugee responsive teaching competencies was poor and this was expected since EFL prospective teachers did not receive any training related to refugee education. After experiencing the training unit, the EFL prospective 
teachers' knowledge of refugee responsive teaching competencies was significantly improved. The underlying possibility behind this result may be due to the fact that the suggested module was short but well-tailored in terms of its content, training activities, training delivery. YouTube videos were interesting and motivating and this increased EFL prospective teachers' engagement and achievement. Another possibility is that the researcher specialized in TEFL and acted as a trainer; he was wellacquainted with the participants

\section{Conclusion}

It is evident that the identified refugee learners' needs go in line with the pertinent literature. There is a consensus among the in-service teachers of refugees on the identified refugee learners' needs. Refugee responsive teaching competencies were formulated in light of the identified refugee learners' needs and Vygotsky's sociocultural theory. Training EFL students on refugee responsive teaching competencies develops their knowledge of teaching EFL to refugee learners and multi-culture EFL classrooms. Accordingly, the suggested RRTM is recommended to be an innovative part of the curriculum of the current EFL teacher preparation programs.

\section{Limitations of the study}

The present study has some apparent limitations. The first is generalizability. Findings cannot be generalized to the huge number of Syrian refugee learners in Egypt. The sample size of Syrian refugee learners participated in Needs Assessment was limited. Similarly, only 76 EFL student teachers participated in experimental phase of the study so the findings of the RRT competencies awareness cannot be generalized all over the Egyptian Faculty of Education students. Caution is required since the study phases were conducted in the Covid-19 pandemic time and this made the recruitment of the sample and experimentation were more challenging. However the RRTM was proposed to meet the needs of the EFL student teachers who are willing to work in multi-culture schools, student teachers of other majors can use the same module with little modifications.

\section{References}

Alefesha, Heba \& Al-Jamal Dina (2019). Syrian Refugees' Challenges and Problems of Learning and Teaching English as a Foreign Language (EFL): Jordan as an Example. Journal of Ethnic and Cultural Studies, Vol. 6, No. 1, 117-129 ISSN: 2149-1291

Birman, D. and N. Tran (2017). When worlds collide: Academic adjustment of Somali Bantu learners with limited formal education in a U.S. elementary school, International Journal of Intercultural Relations, Vol. 60, pp. 132-144.

Bonin, H. (2017). The Potential Economic Benefits of Education of Migrants in the EU, Publishing Office of the European Union.

Bunar, N. et al. (2018). Hope: Education for Newcomers in Europe, Education International, Brussels. https://issuu.com/educationinternational/docs/28 feb doc web

Bush, K. and Saltarelli, D. (2000). The two faces of education in ethnic conflict. Florence: UNICEF Innocenti Research Centre.

Carlson, B., Cacciatore, J. \& Klimek, B (2012). A Risk and Resilience Perspective on Unaccompanied Refugee Minors, Social Work, Vol. 57/3, pp. 259-269.

Cassity, E. and G. Gow (2006). Making Up for Lost Time: The Experiences of Southern Sudanese Young Refugees in High Schools, Youth Studies Australia, Vol. 24/3, pp. 51-55. 
Catarina, E. \& Maaike H. (2019). Integrating Syrian refugee teachers into Swedish educational labour market reflections on a fast track design, Education Inquiry, 10:4, 385-403, https://doi.org/10.1080/20004508 .2019 .1579625

Cinkara, E. (2017). The role of L+ Turkish and English learning in resilience: A case of Syrian learners at Gaziantep University. Journal of Language and Linguistic Studies, 13(2), 190-203.

Correa-Velez, I., Gifford and McMichael, C. (2015). The persistence of predictors of wellbeing among refugee youth eight years after resettlement in Melbourne, Australia, Social Science \& Medicine, Vol. 142, pp. 163168. http://dx.doi.org/10.1016/j.socscimed.2015.08.017

Crul, M. et al (2019). How the different policies and school systems affect the inclusion of Syrian refugee children in Sweden, Germany, Greece, Lebanon and Turkey. Comparative Migration Studies, 7. https://doi.org/10. 1186/s40878-018-0110-6

Culbertson, S. and Constant, L. (2015). Education of Syrian refugee children: managing the crisis in Turkey, Lebanon, and Jordan. Santa Monica, CA: Rand Corporation.

Dooley, K. (2009). Re-thinking pedagogy for middle school learners with little, no or severely interrupted schooling, English Teaching, Vol. 8/1, pp. 5-22.

Essomba, M. (2017). The right to education of children and youngsters from refugee families in Europe, Intercultural Education, Vol. 28/2, pp. 206-218, https://dx.doi.org/10.1080/14675986.2017.1308659

Frimberger, K. (2016). Towards a well-being focused language pedagogy: Enabling arts-based, multilingual learning spaces for young people with refugee backgrounds. Pedagogy, Culture \& Society, 24(2), 285-299.

Gay, G. (2018). Culturally responsive teaching: Theory, research, and practice. New York, NY: Teachers College Press.

Graham, H., R. Minhas and G. Paxton (2016). Learning problems in children of refugee background: A systematic review, Pediatrics, Vol. 137/6.

Jacobsen, M., M. Demott and T. Heir (2014). Prevalence of psychiatric disorders among unaccompanied asylumseeking adolescents in Norway, Clinical Practice and Epidemioly in Mental Health, Vol. 10, pp. 53-58.

Juvonen, J. \& Bell, A. N. (2018). Social integration of refugee youth in Europe: lessons learnt about interethnic relations in U.S. schools. Polish Psychological Bulletin 49 (1), 23-30.

Karam, F. J., Kibler, A. K., \& Yoder, P. J. (2017). Because even us, Arabs, now speak English: Syrian refugee teachers' investment in English as a foreign language. International Journal of Intercultural Relations, 60, 169-182.

Kirk, J. and Winthrop, R. (2007). 'Supporting teacher development in Northern Ethiopia', International Review of Education, 53 (5/6), 715-723.

Kostoulas-Makrakis, N. \& Makrakis, V. (2020). Developing student driven learning activities to promote refugee quality education through the CARE methodology, International Journal of Early Years Education. https://doi.org/10.1080/09669760.2020.1765091

Kovinthan, T. (2016). Learning and Teaching with Loss: Meeting the Needs of Refugee Children through Narrative Inquiry, Diaspora, Indigenous, and Minority Education, Studies of Migration, Integration, Equity, and Cultural Survival 10 (3), 141- 155. 10:3, 141-155, https://doi.org/10.1080/15595692.2015.1137282

Magos, K. \& Margaroni, M. (2018). The importance of educating refugees. Global Education Review 5(4), 1-6.

Martin, D. B. (2006). Mathematics learning and participation in African American context: The construction of identity in two intersecting realms of experience. In N. Nasir \& P. Cobb (Eds.), Diversity, equity, and access to mathematical ideas (pp. 146-158). New York, NY: Teachers College Press.

Matthews, M. (2008). "Schooling and settlement: refugee education in Australia", International Studies in Sociology of Education, Vol. 18/1, pp. 31-45.

Mogli, M., Kalbeni, S., \& Stergiou, L. (2020). "The teacher is not a magician”: teacher training in Greek reception facilities for refugee education. International e-Journal of Educational Studies (IEJES), 4 (7), 42-55. https://doi.org/10.31458/iejes.605255

Morrice, L., Tip, L., Brown, R. and Collyer. M. (2019). Resettled Refugee Youth and Education: Aspiration and Reality. Journal of Youth Studies, 23(3), pp. 1-18. https://doi.org/10.1080/13676261.2019.1612047 
Nakeyar, C., V. Esses and G. Reid (2017). The psychosocial needs of refugee children and youth and best practices for filling these needs: A systematic review, Clinical Child Psychology and Psychiatry, Vol. 23/2, pp. 186-208, http://dx.doi.org/10.1177/1359104517742188

OECD (2019), Ready to Help?: Improving Resilience of Integration Systems for Refugees and other Vulnerable Migrants, OECD Publishing, Paris. http://dx.doi.org/10.1787/9789264311312-en

Ogilvie, G., \& Fuller, D. (2016). Restorative Justice Pedagogy in the ESL classroom: Creating a caring environment to support refugee learners. TESL Canada Journal, 86-96.

Pastoor, L. (2016). Rethinking refugee education: principles, policies and practice from a European perspective, Annual Review of Comparative and International Education, Vol. 30, pp. 107-116.

Rajab, T. (2015). Socio-cultural study of pedagogical practices inside Syrian EFL classrooms. International Journal of Society, Culture \& Language, 3 (2), 97-114.

Sarmini, I., Topcu, E., Scharbrodt, O. (2020). Integrating Syrian refugee children in Turkey: The role of Turkish language skills: A case study in Gaziantep. International Journal of Educational Research Open. 1 (2020) 100007.

Sleijpen, M. et al. (2016). "Between power and powerlessness: A meta-ethnography of sources of resilience in young refugees", Ethnicity and Health, Vol. 21, pp. 158-180.

Steele, T. (2017). English language teaching to Syrian refugees in transit. Online Journal of English Language Teaching (TOJELT), 2(1), 40-52.

Stewart, J. (2011). Supporting refugee children: Strategies for educators. Toronto, Canada: University of Toronto Press.

Swain, M., Kinear, P., \& Steinman, L. (2015). Sociocultural theory in second language education: An introduction through narratives. Bristol: Multilingual Matters.

UNHCR, (2019). UNHCR Egypt Fact Sheet, http://reporting.unhcr.org/egypt

Vygotsky, L. S. (1978). Mind and society. Cambridge, MA: Harvard University Press.

Watkins, M., G. Noble, and A. Wong. 2018. It is Complex! Working with Students of Refugee Backgrounds and Their Families in New South Wales Public Schools. New South Wales Teachers Federation. https://www.nswtf.org.au/files/18530_its_complex_centenary_report_digital.pdf

Younes, M. \& Morrice, L. (2019). Summary of Challenges Relevant to Refugees' Education in Jordan. Centre for International Education and Development, University of Sussex, Brighton UK. 